\title{
Hepatosplenic abscesses in an immunocompetent child with cat-scratch disease from Peru
}

\author{
Alexis Alfaro del Pozo ${ }^{1}$, Michelle Angulo-Cruzado ${ }^{1}$, Ricardo Amenero-Vega ${ }^{1,2}$, Alexander Álvarez-Lulichac ${ }^{1}$, \\ Hugo Fernández-Cosavalente ${ }^{3,4}$, Joshuan Barboza-Meca ${ }^{5}$ and Alfonso J. Rodriguez-Morales s,7* $^{*}$
}

\begin{abstract}
Background: Cat-scratch disease (CSD) is a zoonotic infection caused by Bartonella henselae and B. clarridgeiae. The typical manifestations of CSD include regional lymphadenitis and fever. However, CSD can have a wide variety of clinical manifestations that can lead to incorrect diagnoses and prolonged hospital stays.

Case presentation: We present a case of a 3-year-old boy admitted to the pediatric service due to prolonged fever and abdominal pain. He received empirical antimicrobial treatment due to suspicion of infection. Abdominal ultrasound showed hepatosplenic abscesses. An IFA detected the presence of IgG antibodies against B. henselae (1:256). Patient was successfully treated with azithromycin and discharged after 7 weeks.

Conclusions: Hepatosplenic abscesses in CSD are rarely reported, particularly in immunocompetent children, with this, only 36 cases in PubMed, Web of Sciences and Scopus bibliographical databases. High rate of suspicion and serological tests availability are of utmost importance in order to detect it and treat it successfully and promptly.
\end{abstract}

Keywords: Cat-scratch disease, Bartonella henselae, Child, Hepatosplenic abscesses, Peru

\section{Background}

Cat-scratch disease (CSD) is an infectious zoonotic disease, usually benign, caused by Bartonella henselae and B. clarridgeiae [1]. The causative agents are gramnegative coccobacilli whose biological cycles involve an intermediate host (often fleas), that maintain transmission between cats [2]. The infected saliva and nails of cats are the main routes of transmission to the human. After inoculation, the bacteria colonize endothelial cells, and then they are released into the bloodstream, where they infect the erythrocytes helped through their virulence factors, such as deformin and motilin that allow the membrane penetration of the red blood cells. Antiapoptotic substances that inhibit the erythrocytic phagosome are also involved, allowing the bacteria to divide

\footnotetext{
*Correspondence: arodriguezm@utp.edu.co; jbarbozameca@relaped.com

${ }^{6}$ Public Health and Infection Research Group, Faculty of Health Sciences,

Universidad Tecnologica de Pereira, Pereira, Risaralda, Colombia

Full list of author information is available at the end of the article
}

and multiply until reaching the critical density that led to clinical disease [3].

The typical form of CSD represents around $90 \%$ of cases. This is characterized by the appearance of self-limiting regional lymphadenopathy, accompanied by rash, and fever. Atypical forms would include myocarditis, endocarditis, osteomyelitis, granulomatous conjunctivitis, encephalomeningitis and the Parinaud oculoglandular syndrome, among others [4]. Liver and splenic lesions are considered a rare form of disease (occurring in less than $10 \%$ of the cases). Liver abscesses are usually unique but can sometimes be multiple and small $(<2 \mathrm{~cm})$, called micro-abscesses [5, 6]. Abscess of the spleen represents a rare CSD clinical form $[7,8]$.

The people generally affected by CSD are children and young adults, having an uncertain incidence and little known even in developed countries [9]. The diagnosis is still complicated. However, the serological tests for Bartonella henselae using enzyme immunoassay (EIA) or indirect fluorescence assay (IFA) has shown excellent 
results. Also, the biopsy can be used for granulomatous observation of the infection or using Warthin-Starry stain [10].

Antimicrobial drugs such as erythromycin, gentamicin, quinolones, doxycycline, azithromycin and trimethoprim/sulfamethoxazole (TMP/SMX) have shown favorable results for its treatment. Albeit of that, many of the cases show a spontaneous resolution [11]. We present a case of CSD in an immunocompetent child from Peru, that developed hepatosplenic abscesses.

\section{Case presentation}

A 3-year-old boy from an urban area of Trujillo, Peru, with no completed vaccines and mild anemia, was admitted to our hospital on March 19, 2018, for persistent fever. The mother indicated that her son has been scratched by a stray cat on the anterior region of the left arm with no apparent signs of inflammation.

Eighteen days before admission, he had a fever of $38.5^{\circ} \mathrm{C}$. The day after, colicky abdominal pain begun. $\mathrm{He}$ was brought to the emergency ward of another hospital where metamizole was administrated and hours later he was discharged.

Sixteen days before admission, in a private consultation, it was diagnosed apparently with a food poisoning, and he was treated again with metamizole. At this point the fever ceased. Fifteen days before admission, the mother indicated that he had an episode of diarrhea, without mucus or blood, also presenting nausea.

Thirteen days before admission, the fever appeared again, now accompanied with non-productive cough. In a private consultation he was diagnosed with an acute respiratory infection, and was treated with amoxicillinclavulanic acid $(75 \mathrm{mg} / \mathrm{kg} /$ day $)$ until his hospitalization, without significant improvement.

The day of the admission to our hospital, his physical exam revealed fever $\left(38.5^{\circ} \mathrm{C}\right)$, pallor $(+/+++)$, a no congestive pharynx and soft and depressible abdomen. His vital signs include a respiratory rate of 24 breaths/ $\mathrm{min}$, a cardiac rate of 106 beats $/ \mathrm{min}$, an $\mathrm{SO}_{2}$ of $96 \%$ and a $\mathrm{FiO}_{2}$ of $21 \%$. No signs of regional lymphadenitis were observed. At this point, fever of unknown origin (FUO) was suspected. Laboratory tests at income revealed mild anemia, mild thrombocytosis, prolonged coagulation times, including increase fibrinogen and an increased C-Reactive Protein (Table 1).

The first day of hospitalization, he presented microscopic hematuria, abdominal pain, and persistent fever. An abdominal ultrasound revealed mild hepatomegaly with multiple hypoechogenic formations with nondefined borders $<11 \mathrm{~mm}$ at liver, as well as also at spleen,
Table 1 Admission laboratory tests

\begin{tabular}{lll}
\hline Tests & Results & Reference values \\
\hline $\begin{array}{ll}\text { Complete blood count } \\
\text { Hemoglobin }\end{array}$ & $10.7 \mathrm{~g} / \mathrm{dL}$ & $\geq 11 \mathrm{~g} / \mathrm{dL}$ \\
Leukocytes & $8.19 \times 10^{3}$ & $5.5-15.5 \times 10^{3}$ \\
& $(\mathrm{~B}: 3, \mathrm{~S}: 53, \mathrm{~N}: 56 \%)$ & $(\mathrm{N}: 25-57 \%)$ \\
Platelets & $413 \times 10^{3}$ & $150-400 \times 10^{3}$ \\
Coagulation profile & & \\
PT & $13.6 \mathrm{~s}$ & $10.6-11.4 \mathrm{~s}$ \\
INR & 1.24 & $0.8-1.2$ \\
Fibrinogen & $470 \mathrm{mg} / \mathrm{dL}$ & $170-400 \mathrm{mg} / \mathrm{dL}$ \\
PTT & 42.9 & $24-36 \mathrm{~s}$ \\
Urinalysis & & \\
Leukocytes & $1-3 \mathrm{per}$ field & $0-4 \mathrm{per} \mathrm{field}$ \\
Germs & Negative & Negative \\
Transaminases & & $10 \mathrm{a} 40 \mathrm{U} / \mathrm{L}$ \\
GOT & $31 \mathrm{U} / \mathrm{L}$ & $10 \mathrm{a} 34 \mathrm{U} / \mathrm{L}$ \\
GTP & $19 \mathrm{U} / \mathrm{L}$ & $\mathrm{mg} / \mathrm{dL}$ \\
CRP & $66 \mathrm{mg} / \mathrm{dL}$ & \\
\hline Bbands & &
\end{tabular}

$B$ bands, $S$ segmented, $N$ neutrophils, $P T$ prothrombin time, INR international normalized ratio, PTT partial thromboplastin time, GOT serum glutamic oxaloacetic transaminase or aspartate transaminase (AST), GPT serum glutamic pyruvic transaminase or alanine aminotransferase (ALT), CRP C-reactive protein

of $<10 \mathrm{~mm}$ in the spleen, suggesting hepatosplenic micro-abscesses (Fig. 1).

At day four, treatment with ceftriaxone $(81 \mathrm{mg} / \mathrm{kg} /$ day) and metronidazole $(30 \mathrm{mg} / \mathrm{kg} /$ day $)$ was started. On the seventh day of hospitalization, ceftriaxone was changed to imipenem $(75 \mathrm{mg} / \mathrm{kg} /$ day $)$. Although that, fever persisted for 3 days. Additional laboratory tests at this moment included blood culture for bacteria and fungi, STORCH serologies (VDRL, FTA-Abs, toxoplasmosis, rubella, CMV and EBV, HSV-1, HSV-2), ELISA for HIV, PPD, acid fast bacilli (AFB) from sputum, as well as agglutination tests for Bartonella bacilliformis and Salmonella. All these tests were negative. An indirect immunofluorescence antibodies (IFA) assay tested positive for IgG against $B$. henselae (titers 1:256) confirming the diagnosis of CSD. Therapy with imipenem and metronidazole was stopped and treatment with azithromycin $(10 \mathrm{mg} /$ $\mathrm{kg} /$ day) was initiated. One day later fever ceased.

On the tenth day, an abdominal CT-scan with contrast showed irregular hypovascular nodules of 4.8, 4.6 and $6.5 \mathrm{~mm}$ in the liver, in segments II, III and VI, and spleen till $10 \mathrm{~mm}$, confirming the ultrasound findings of micro-abscesses. On the day fifteen, a follow-up ultrasound showed augmented hypoechogenic images in the liver up to $19 \mathrm{~mm}$ in segments IV and II of the liver, and up to $10 \mathrm{~mm}$ in the spleen (Fig. 2). Two weeks later an 


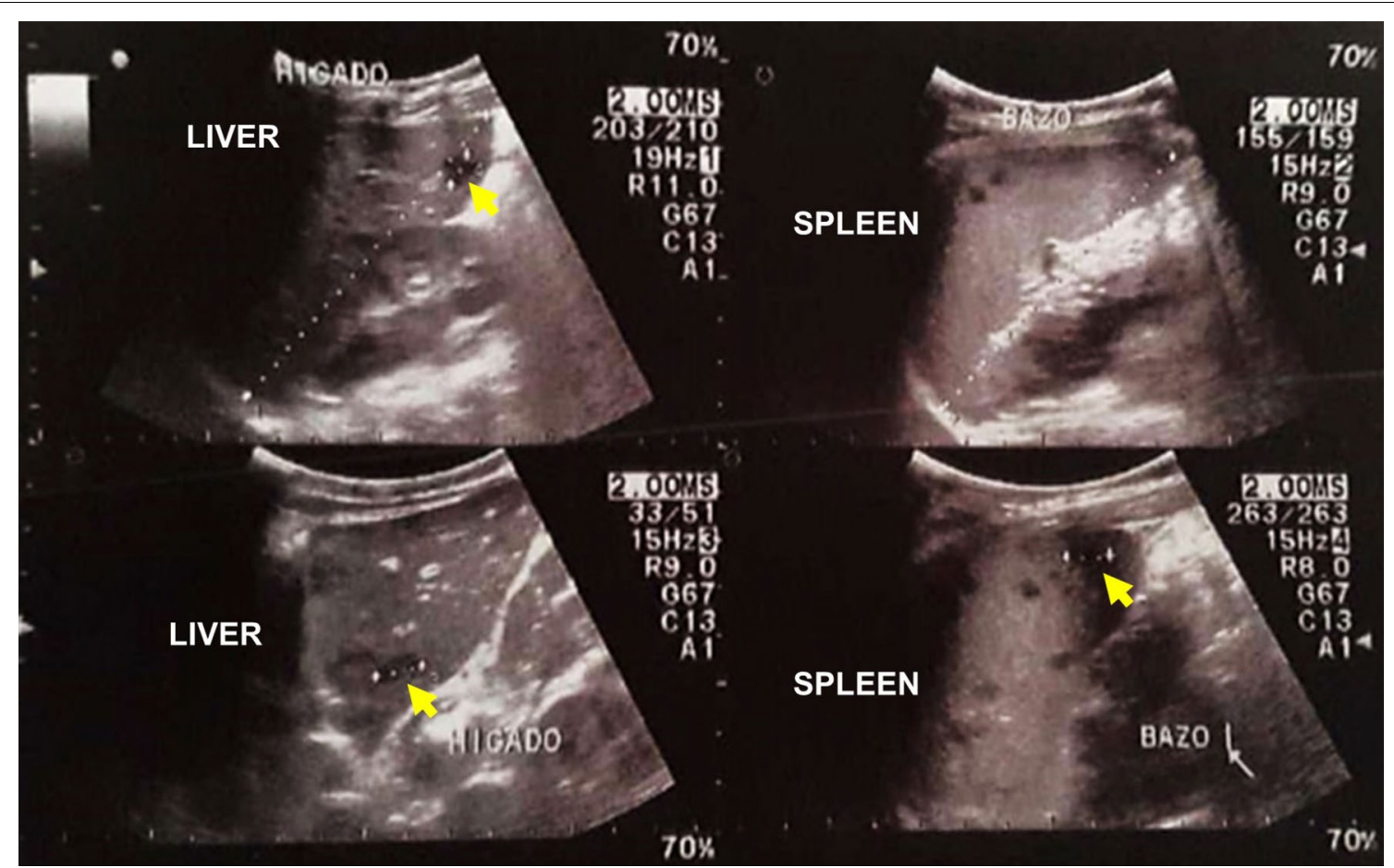

Fig. 1 Abdominal ultrasound showing multiple hypoechoic areas with poorly defined edges of up to $11 \mathrm{~mm}$ in the liver and in the spleen (yellow arrows indicate the lesions)

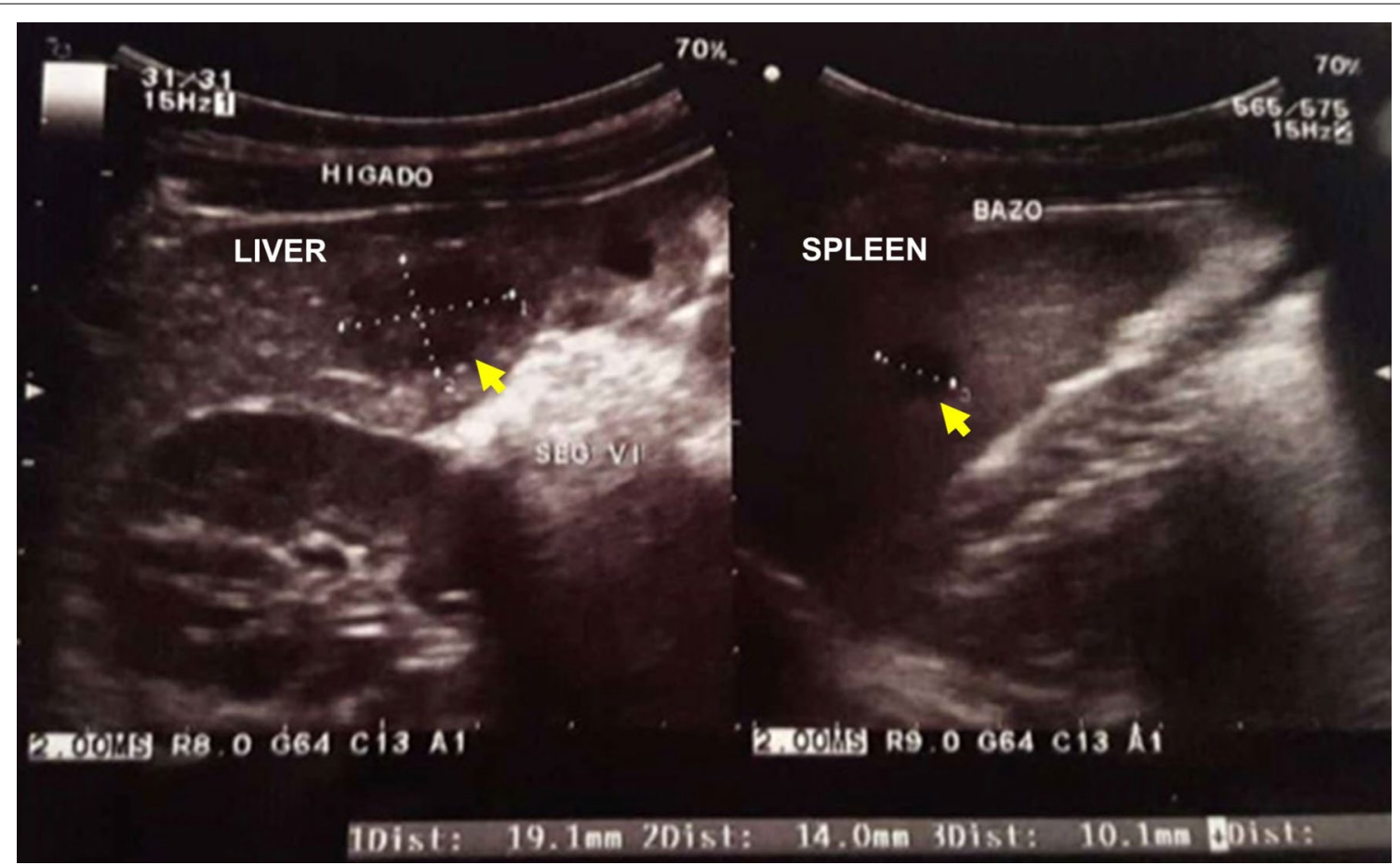

Fig. 2 Follow-up ultrasound showing hepatic lesions increased up to $19.1 \mathrm{~mm}$ in segments IV and II. Spleen lesions persisted (10.1 mm of diameter) (yellow arrows indicate the lesions) 
additional follow-up ultrasound showed a significant decrease on size of the micro-abscesses.

Then, 2 weeks after finished the antimicrobial therapy and 50 hospitalization days, the patient was discharged. Follow-up till 8 weeks after discharge show no further related alterations.

\section{Discussion}

In CSD, the age-groups more frequently affected are children and adolescents [12]. Although in immunocompetent patients, regional lymphadenitis and fever are common findings, our patient did not present the first [13]. Atypical forms of CSD can have a variety of manifestations including systemic compromise, myocarditis, endocarditis, osteomyelitis and encephalomeningitis, but also hepatosplenic micro-abscesses and are supposed to occur in less than $10 \%$ of the cases [14]. Hepatosplenic micro-abscesses are rarely reported in the literature $[7,8$, $15-17]$, especially in children $[15,18]$. Although would be considered an old condition [19, 20], current and other recent cases call for keep in mind as a differential diagnosis in adults as well as in children with persistent fever, abdominal pain and lesions at abdominal ultrasound, but particularly on a uncommon clinical presentation. After a comprehensive review of bibliographical databases, PubMed, Web of Sciences and Scopus, we were able to find six previous publications (Table 2). Four of them corresponded to case reports including five cases, and two case series that contain 30 cases, then, summarizing 35 cases previously published cases of immunocompetent children with CSD developing hepatosplenic abscesses (Table 2). The time span of these reports was 17 years, from 1999 to 2016, most of them being from United States (33 out of 35 cases). No previous cases from a Latin American country have been reported. Most patients (22), received rifampin, whilst our case evolved also successfully after treatment with azithromycin. The final outcome of all the reported cases, as well as ours, was cure (Table 2).

Atypical clinical manifestations of CSD would make the diagnosis a difficult task in certain cases, as this is not mostly considered in the differential etiologies. However, history of contact with cats and persistent fever, with serological tests availability help in the clinical and etiological diagnosis [3, 16, 19-21], but given the previous reported cases, evidence of hepatosplenic micro-abscesses would be associated with CSD. Some cases would also develop granulomatous hepatitis with increase in the hepatic transaminases [22]. In our case, patient transaminases remained normal.
The literature points out that clinical criteria such as primary dermal or ocular injury associated with scratching of a cat, presence of local lymphadenopathies close to the scratch and fever are considered in the diagnosis of CSD. But cases, such as ours, can present without ocular or lymphatic alterations.

In addition, laboratory tests that rule out other etiologies should be included. Serological tests, such as the IFA has higher sensitivity and specificity [23]. If possible, tissue biopsies of lymph nodes stained with Warthin-Starry are also helpful in the CSD diagnosis [24]. Serological tests with values higher than 1:64 for IgG and 1:15 for IgM confirm the CSD diagnosis [21].

In recent years, PCR has also proved to be a useful diagnostic tool [25]. Imaging studies are necessary and helpful, especially with abdominal symptoms. CT-scan is the recommended, although ultrasound by an experienced professional has a good diagnostic value and is useful in monitoring, as we did in our case [26].

Appropriate antibiotic treatment of CSD in pediatrics is not well established [27], but azithromycin, as we used, appeared to be the best choice [27]. TMP/SMX may be considered as an alternative antibiotic when azithromycin cannot be used $[11,27]$.

Unfortunately, routine diagnosis and surveillance of CSD as well as of bartonelloses are not done in Peru and most countries in Latin America, where they are prevalent [28-30]. No previous case of CSD associated with hepatosplenic abscesses nor in children nor in adults was reported before. Even more, CSD and other bartonelloses forms are also neglected in terms of research in the region [29]. Then, surveillance should be established in order to estimate the real prevalence and the real cause of multiple pathologies and their atypical presentations, including FUO, particularly in tropical and subtropical countries [31]. In one of the two case series, CSD was not the initial diagnosis in any of these cases. Five children were referred for evaluation of FUO, but other diagnoses included Kawasaki disease, sinusitis, pyelonephritis, collagen vascular disease, tonsillitis and pharyngitis [19].

Given the high prevalence of infection in cats reported in different studies of CSD [32], and its associated risk as zoonotic disease [33], it is necessary to draw the attention and awareness among the medical community about this differential diagnosis as well as their different clinical presentations and history of contacts with cats, but also with other animals. It is worthy to mention that in addition to cats, also dogs [34], rodents [35] and probably other domestic and peridomestic animals would be infected with Bartonella 


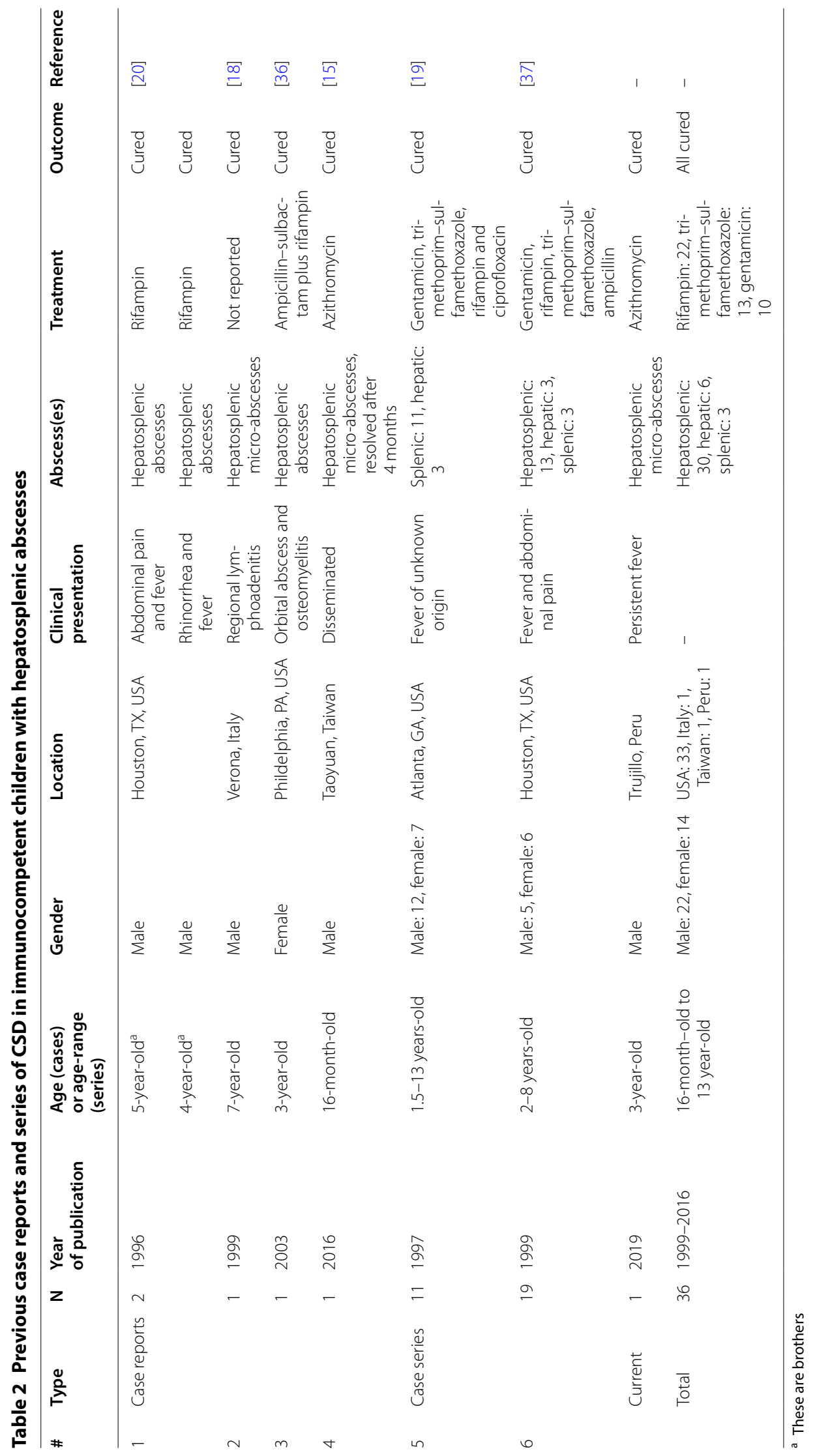


henselae and should be considered regard the zoonotic risk for humans especially with clinical manifestations.

\section{Acknowledgements}

None.

\section{Authors' contributions}

HFC, AAP, MAC and RAV treated the patient. JBM guided the accurate diagnosis. AJRM wrote the first draft of the manuscript. AAdP, MAC, RAV, AAL conceived the report, collected data, analyzed and interpreted clinical data. HFC, $J B M$, and AJRM write the first and second draft. JBM and AJRM performed a systematic review. All authors read and reviewed the subsequent versions of the manuscript. All authors read and approved the final manuscript.

\section{Funding}

None.

\section{Availability of data and materials}

Copy of the clinical data of the patient is available.

\section{Ethics approval and consent to participate}

Written consent from the patient's mother was obtained.

\section{Consent for publication}

Written consent from the patient's mother was obtained for publication.

\section{Competing interests}

The authors declare that they have no competing interests.

\section{Author details}

${ }^{1}$ Faculty of Human Medicine, Universidad Nacional de Trujillo, Trujillo, Peru.

${ }^{2}$ Sociedad Cientifica de Estudiantes de Medicina, Universidad Nacional de Trujillo, Trujillo, Peru. ${ }^{3}$ Department of Pediatrics, Faculty of Human Medicine, Universidad Nacional de Trujillo, Trujillo, Peru. ${ }^{4}$ Department of Pediatrics, Hospital Belen de Trujillo, Trujillo, Peru. ${ }^{5}$ Universidad San Ignacio de Loyola, Lima, Peru. ${ }^{6}$ Public Health and Infection Research Group, Faculty of Health Sciences, Universidad Tecnologica de Pereira, Pereira, Risaralda, Colombia. ${ }^{7}$ Universidad Privada Franz Tamayo/UniFranz, Cochabamba, Bolivia.

\section{Received: 25 April 2019 Accepted: 6 July 2019}

\section{Published online: 15 July 2019}

\section{References}

1. Marques LC, Pincerato K, Yoshimura AA, Andrade FEM, de Barros A. Cat scratch disease presenting as axillary lymphadenopathy and a palpable benign mammary nodule mimicking a carcinoma. Rev Soc Bras Med Trop. 2018:51(2):247-8.

2. Nelson CA, Moore AR, Perea AE, Mead PS. Cat scratch disease: US clinicians' experience and knowledge. Zoonoses Public Health. 2018;65(1):67-73.

3. Mathews DM, Vance KM, McMahon PM, Boston C, Bolton MT. An atypical case of Bartonella henselae osteomyelitis and hepatic disease. Case Rep Pediatr. 2018:2018:2750275.

4. Yanagihara M, Tsuneoka H, Tanimoto A, Otsuyama K, Nishikawa J, Matsui T, Nojima J, Ichihara K. Bartonella henselae DNA in seronegative patients with cat-scratch disease. Emerg Infect Dis. 2018:24(5):924-5.

5. Kwon HY, Park YK, Lee SM, Baek JH, Kang JS, Chung MH, Kim EJ, Lee JS. Characterization of clinical isolates of Bartonella henselae strains, South Korea. Emerg Infect Dis. 2018;24(5):912-5.

6. Bachler P, Baladron MJ, Menias C, Beddings I, Loch R, Zalaquett E, Vargas M, Connolly S, Bhalla S, Huete A. Multimodality imaging of liver infections: differential diagnosis and potential pitfalls. Radiographics. 2016;36(4):1001-23.

7. Anyfantakis D, Kastanakis M, Papadomichelakis A, Petrakis G, Bobolakis E. Cat-scratch disease presenting as a solitary splenic abscess in an immunocompetent adult: case report and literature review. Infez Med. 2013:21(2):130-3.
8. Aoki Y, Kitazawa K. Cat-scratch disease with hepatosplenic lesions in two brothers. IDCases. 2016:4:13-4.

9. Gonzalez S, Parra A, Mussini S, Buchovsky A, Berberian G. Cat scratch disease in children, a five year study in a pediatric tertiary hospital. Int J Infect Dis. 2018;73:328.

10. Zouari S, Khrouf F, M'Ghirbi Y, Bouattour A. First molecular detection and characterization of zoonotic Bartonella species in fleas infesting domestic animals in Tunisia. Parasites Vectors. 2017;10:436.

11. Umbreen G, Jabeen C. Case reports of cat scratch disease with typical and atypical clinical manifestations: a literature review. Int J Med Res Health Sci. 2017:6(4):51-4.

12. Tapia MF, Rosas R, Schiappacasse G, Thompson L. Bartonella henselae infection, the importance of images for diagnosis and follow-up. Rev Chil Infectol. 2017:34(4):410-2.

13. Tan CL, Fhun LC, Tai ELM, Gani NHA, Muhammed J, Jaafar TNT, Tajudin LSA, Hitam WHW. Clinical profile and visual outcome of ocular bartonellosis in Malaysia. J Trop Med. 2017;2017:1-6.

14. Rodriguez-Rodriguez M, Rodriguez-Rosell MV, Blanco-Costa MI, Rodriguez-Asensio J. Cat scratch disease. Presentation of several clinical cases. Aten Prim. 2017:49(3):196-7.

15. Chang CC, Lee CJ, Ou LS, Wang CJ, Huang YC. Disseminated cat-scratch disease: case report and review of the literature. Paediatr Int Child Health. 2016;36(3):232-4.

16. Garcia JC, Nunez MJ, Castro B, Fernandez JM, Lopez A, Portillo A, Oteo JA. Hepatosplenic cat scratch disease in immunocompetent adults: report of 3 cases and review of the literature. Medicine. 2014:93(17):267-79.

17. Knafl D, Lotsch F, Burgmann H, Goliasch G, Poeppl W, Ramharter M, Thalhammer F, Schuster C. Hepatosplenic abscesses and osteomyelitis of the spine in an immunocompetent adult with cat scratch disease. Case Rep Infect Dis. 2015:2015:317260

18. Luciano A, Rossi F, Bolognani M, Trabucchi C. Hepatic and splenic micro-abscess in cat scratch disease. Report of a case. Pediatr Med Chir. 1999;21(2):89-91.

19. Dunn MW, Berkowitz FE, Miller JJ, Snitzer JA. Hepatosplenic cat-scratch disease and abdominal pain. Pediatr Infect Dis J. 1997;16(3):269-72.

20. Tan TQ, Wagner ML, Kaplan SL. Bartonella (Rochalimaea) henselae hepatosplenic infection occurring simultaneously in two siblings. Clin Infect Dis. 1996;22(4):721-2.

21. Pawlowska-Iwanicka K, Podsiadlowicz-Borzecka M, Stelmach I. Cat scratch disease in a 8-year-old boy—a case report. Pediatr Med Rodz. 2016:12(4):451-4.

22. VanderHeyden TR, Yong SL, Breitschwerdt EB, Maggi RG, Mihalik AR, Parada JP, Fimmel CJ. Granulomatous hepatitis due to Bartonella henselae infection in an immunocompetent patient. BMC Infect Dis. 2012;12:17.

23. Zbinden R. Bartonella henselae-based indirect fluorescence assays are useful for diagnosis of cat scratch disease. J Clin Microbiol. 1998:36(12):3741-2.

24. Valtierra MA, Valencia CS, Negro HF, Galarza AU, Somarriba BF, Somarriba F, Kassab NH. Molecular epidemiology of Bartonella henselae in stray and sheltered cats of Zaragoza, Spain. Rev Esp Salud Publica. 2016;90:E5

25. Hobson C, Le Brun C, Beauruelle C, Maakaroun-Vermesse Z, Mereghetti L, Goudeau A, Lanotte P. Detection of Bartonella in cat scratch disease using a single-step PCR assay kit. J Med Microbiol. 2017:66(11):1596-601.

26. Nelson CA, Saha S, Mead PS. Cat-scratch disease in the United States, 2005-2013. Emerg Infect Dis. 2016;22(10):1741-6.

27. Shorbatli LA, Koranyi KI, Nahata MC. Effectiveness of antibiotic therapy in pediatric patients with cat scratch disease. Int J Clin Pharm. 2018:40(6):1458-61.

28. Bolivar-Mejia A, Alarcon-Olave C, Rodriguez-Morales AJ. Skin manifestations of arthropod-borne infection in Latin America. Curr Opin Infect Dis. 2014;27(3):288-94.

29. Culquichicon C, Ramos-Cedano E, Helquero-Santin L, Nino-Garcia R, Rodriguez-Morales AJ. Research trends in Carrion's disease in the last 60 years. A bibliometric assessment of Latin American scientific production. Infez Med. 2018;26(1):28-36.

30. Urrutia LC, Patino-Barbosa AM, Arroyave-Valencia F, Sabogal-Roman JA, Cardona-Ospina JA, Rodriguez-Morales AJ. Oroya fever, verruga 
peruana, and other bartonelloses incidence rates in Colombia (2009-2013). Cureus. 2018;10(10):e3528.

31. King KY, Hicks MJ, Mazziotti MV, Eldin KW, Starke JR, Michael M. Persistent cat scratch disease requiring surgical excision in a patient with MPGN. Pediatrics. 2015;135(6):E1514-7.

32. Barradas PF, de Sousa R, Vilhena H, Oliveira AC, Luz MF, Granada S, Cardoso L, Lopes AP, Goncalves H, Mesquita JR, et al. Serological and molecular evidence of Bartonella henselae in cats from Luanda city, Angola. Acta Trop. 2019;195:142-4.

33. Huarcaya E, Maguina C, Merello J, Cok J, Birtles R, Infante B, Vidal J, Tello A, Ventosilla P. A prospective study of cat-scratch disease in Lima-Peru. Rev Inst Med Trop Sao Paulo. 2002;44(6):325-30.

34. Muller A, Soto F, Sepulveda M, Bittencourt P, Benevenute JL, Ikeda P, Machado RZ, Andre MR. Bartonella vinsonii subsp. berkhoffii and B. henselae in dogs. Epidemiol Infect. 2018;146(9):1202-4.
35. Helan JVG, Grinberg A, Gedye K, Potter MA, Harrus S. Molecular detection of Bartonella coopersplainsensis and B. henselae in rats from New Zealand. N Z Vet J. 2018;66(5):257-60.

36. Mirakhur B, Shah SS, Ratner AJ, Goldstein SM, Bell LM, Kim JO. Cat scratch disease presenting as orbital abscess and osteomyelitis. J Clin Microbiol. 2003;41(8):3991-3.

37. Arisoy ES, Correa AG, Wagner ML, Kaplan SL. Hepatosplenic cat-scratch disease in children: selected clinical features and treatment. Clin Infect Dis. 1999;28(4):778-84.

\section{Publisher's Note}

Springer Nature remains neutral with regard to jurisdictional claims in published maps and institutional affiliations.
Ready to submit your research? Choose BMC and benefit from:

- fast, convenient online submission

- thorough peer review by experienced researchers in your field

- rapid publication on acceptance

- support for research data, including large and complex data types

- gold Open Access which fosters wider collaboration and increased citations

- maximum visibility for your research: over $100 \mathrm{M}$ website views per year

At BMC, research is always in progress.

Learn more biomedcentral.com/submissions 